\title{
Suggesting the Enhanced Lakatosian Conflict Map for Science Teaching
}

\author{
Jun-Young $\mathrm{Oh}^{1}$ \\ ${ }^{1}$ Center for Integrated General Education, Hanyang University, Seoul, Republic of Korea \\ Correspondence: Jun-Young Oh, Center for Integrated General Education, Hanyang University, Seoul, 133-791, \\ Republic of Korea. E-mail: jyoh3324@hanyang.ac.kr
}

Received: February 2, 2014

Accepted: April 25, 2014 Online Published: June 25, 2014

doi:10.5539/ass.v10n13p16

URL: http://dx.doi.org/10.5539/ass.v10n13p16

\begin{abstract}
This study is to suggest teaching strategies and procedures based on Lakatosian heuristic principle through suggested enhanced Lakatosian Conflict Map. Kuhn's philosophy and history of science has been widely influential, but in this research it is argued that it is more appropriate to consider constructivist research within Science Education as 'Research Program' in the sense used by I. Lakatos. The Lakatosian Conflict Map applied in this research could help teachers understand the Cognitive dissonance between their students' existing ideas and target scientific concepts
\end{abstract}

Keywords: Lakatosian heuristic principle, teaching strategies and procedures, Kuhn's philosophy and history of science

\section{Introduction}

Conceptual change is a central issue for those interested in learning. In the educational context, many curriculum targets can be understood in conceptual terms. Young people do not enter school knowing these things, and -just as significantly- they usually come to class (at least in science, and probably in most academic subjects) holding a wide range of ideas that are not entirely consistent with target knowledge (Duit, 2009; Tabler, 2009). The teacher's role then (at least in part) is to facilitate conceptual change.

According to Taber (2009), it can certainly be argued that research into topic such as conceptual change can be considered to be science, at least following a Lakatosian heuristic principle, because Lakatos (1970) would acknowledge that competing research programs can co-exist within a field over extended periods without a dominant paradigm developing to exclude its competitors. Taber $(2006,2009)$ have argued that when considering the field of science education, it is possible to identify a hard core of common assumptions underpinning a good deal of work into learning and teaching in science, to the extent that work can be considered to fit within a common research program.

Thus it makes sense to view the students' theoretical structure as a research program in the Lakatosian sense, as suggested by Niaz (1998). In this context, students' concepts are arranged around an obstinate hard core as well as a flexible protective belt. Students' progress in a course can then is thought of as a conflict between the students' research program and the research program espoused by their textbook and their teacher.

\subsection{Research Questions}

This study were to suggest teaching strategies and their teaching procedures, based on Lakatosian heuristic principle, to achieve the goal the specific research questions underlying the study were the following:

a) Why should we apply Lakatosian heuristic principle to science teaching classroom?

b) How can an appropriate Lakatosian conflict map be developed?

\section{Lakatosian Heuristic Principles as Teaching Strategies}

\subsection{Lakatosian Scientific Research Program}

For Lakatos, the development of scientific theories was shaped by large frameworks of thought called "research programs". A research program will present different theories at different times. 
According to Lakatos, research programs consist of two distinct elements that guide research in distinct ways. One element (the negative heuristic) tells the scientist that path of research to avoid. The other (the positive heuristic) suggests which pathways should be pursued. By the word heuristic, Lakatos means 'a way of doing things', that is, a methodology. Thus, the negative heuristic is simply the decision that certain key assumptions of the research program will go unquestioned. These assumptions represent the so-called hard core of the research program. Lakatos considers the important theories of a research program to be protected by a belt of 'auxiliary hypotheses' and other ideas about which the scientific community is prepared to take a more flexible attitude. The positive heuristic is simply the set of informal guide-lines which suggest how this protective belt might be investigated, and where modifications might be made in order to resolve any anomalies thrown up by the program of research. It is within this protective belt that refutation can easily take place, but while these subsidiary ideas may be replaced, they are modified in such a way that the hard core is maintained (Haines-Young \& Petch, 1986, pp. 88-89).

According to Lakatos (1970, p.123), Empirical progress can be with theoretical progress. He states "Empirical and theoretical progress are inseparably connected".

Figure 1 illustrates how in a "progressive" Lakatosian scientific research program, the core must be conservative, and adequate experimental and mathematical techniques are added continuously to the protective belt (Losee, 2001 p. 203; Chalmers, 1999 p. 133). This illustrates the projection of different theories by the research program at different times.

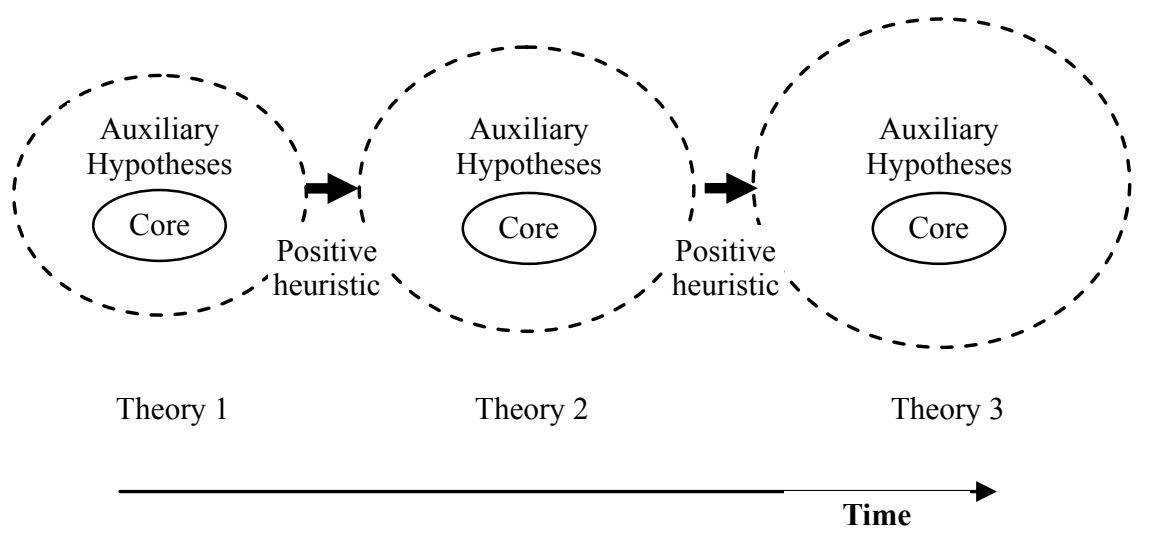

Figure 1. Evolution of scientific theory based on Lakatosian research program (Losee, 2001, p.203)

\subsection{The Necessity of Research Program}

Posner et al. (1982) suggested conditions of conceptual change that are similar to those for Kuhn's scientific paradigm shift (Feldman, 2000. It appears that Kuhn's ideas continue to be important for research in science education and the transition to other philosophies is a slow process.

For Kuhn (1970) scientific growth is based on the change of one paradigm by another, through a process of chaotic upheaval or scientific revolution. Furthermore, different paradigms are incommensurate, central beliefs of scientists do not accept rational arguments among different research programs. In contrast to Kuhn, Lakatos (1970) conceptualizes scientific progress through progressive 'problem-shifts', which is transition which increases the heuristic (explanatory) power of the research programs.

If our test implication is false, we know either that our hypothesis is false or our auxiliary assumption is false. But not test implication does not tell us which one is false. In fact, it is, logically speaking, impossible to falsify a hypothesis since one may always save the hypothesis by abandoning one's auxiliary assumption. This is now known as the Duhem-Quine thesis (Kitchener, 1999, pp. 371-372).

\subsection{The Necessary of Lakatosian Conceptual Change Teaching Strategy}

Given the parallel between the process of theory development by scientists and an individual's acquisition of knowledge ( Duschil \& Gitomer, 1991; Kitchener, 1987), it is not surprising that students resist changes in their major theoretical frameworks. According to Barker and Gholson (1984, p. 228), research programs '....desribed by Lakatos can readily be identified in the history of the psychology of learning and show that the pattern of historical development in the last 50 years conforms to the Lakatosian review. 
According to Taber (2009, Chapter 4), "my research also is that adopting hard-core assumptions is the key demarcation criterion to be used in making the basic premises of teaching sequence model. A study aligned with the hard-core assumptions will logically be influenced by the program's heuristic, inherently if not necessarily explicitly. These premises would seem to represent the basic commitments shared by those doing research in science education field" (p. 122).

It will be argued here that those working in the constructivist Research program in Science Education have offered a follow range of answers to these questions.

Tsai's conflict map (Tsai, 2000; Tsai \& Chang, 2005) is an extension of the map in Hashweh's paper and is produced by adding some other concepts and perceptual support for the target scientific concepts.

However, in spite of these concentrated research activities, we still lack adequate explanations of teaching sequences involving distinct strategies. Tsai's conflict sequence always presents critical events after introducing scientific concepts. It has paradigms of Kuhn metrology rather than research program of Lakatosian mythology. Tsai's conflict map did not clarify the middle stage in changing from students' alternative conception to scientific concepts, all instant rationality theory failed, and rationality functions slowly, according to Lakatos., in accidence, our study set a tentative research program called 'Naïve scientific conception'(Oh et al. 2009; Oh, 2011)

It thus makes sense to view the students' theoretical structure as a research program in the Lakatosian sense as suggested by Niaz (1998). In this context, students' concepts are arranged around an obstinate hard core as well as a flexible protective belt . Students' progress in a course can then be thought of as a conflict between the students' research program and the research program espoused by their textbook and their teacher.

However, the Lakatosian research program is modified only when other competitive research program are needed. Therefore, it is necessary to present critical events for alternative conceptions and competitive theories before presenting new competitive theories. Even if discrepant events are presented, we cannot easily expect dissatisfaction. Therefore, it is necessary to consider intermediate steps that can weaken alternative conceptions.

For science educator, The crux of the issue is that the Lakatosian framework considers competing research programs as essential for progress and at the same time commensurable. If understand as paradigms in the Kuhnian philosophy, lead to situations that are not conducive to debate as Kuhn's (1970) incommensurability thesis implies that any one science can accommodate only one paradigm.

A Lakatosian conceptual change teaching strategies (this study being an example) after having identified the hard and the soft core of students' beliefs will look for 'auxiliary hypotheses' that students use to protect core beliefs and subsequently introduce/construct alternative explanations that contradict their original beliefs.

\section{Suggesting Lakatosian Conflict Map (Modified from Oh, 2011, Oh, 2014)}

In this research, the procedural model (so called, Lakatosian conflict map) involving teaching strategies for scientific concepts based on the framework of Lakatosian heuristic principles are proposed.

\subsection{Examine the Students' Existing-Conceptions}

Searching the student's core conceptions and protective belt (related concepts and protecting perceptions) on a topic by discrepant events can be a very well starting point for teaching procedures.

\subsection{Suggesting the Scientific Concept}

$\mathbf{1}^{\text {st }}$, Students must at least understand about the main theories of the scientific concepts that will be learned for resolving conflict 1 .

$2^{\text {nd }}$, The teaching procedure must use critical events to address conflict 2 .

$\mathbf{3}^{\text {rd }}$, Plausible learning involves students constructing knowledge through their existing conceptions and target scientific concepts.

$4^{\text {th }}$, Fruitful conceptual change requires perceptual supports, examples or phenomena from relevant theories.

\subsection{Checking Conceptual Change}

It should be checked conceptual changes in the hard core of students' initial conceptions. 


\section{Students' Existing Conception}
Naïve Scientific Concept

\section{Target Scientific Concept}

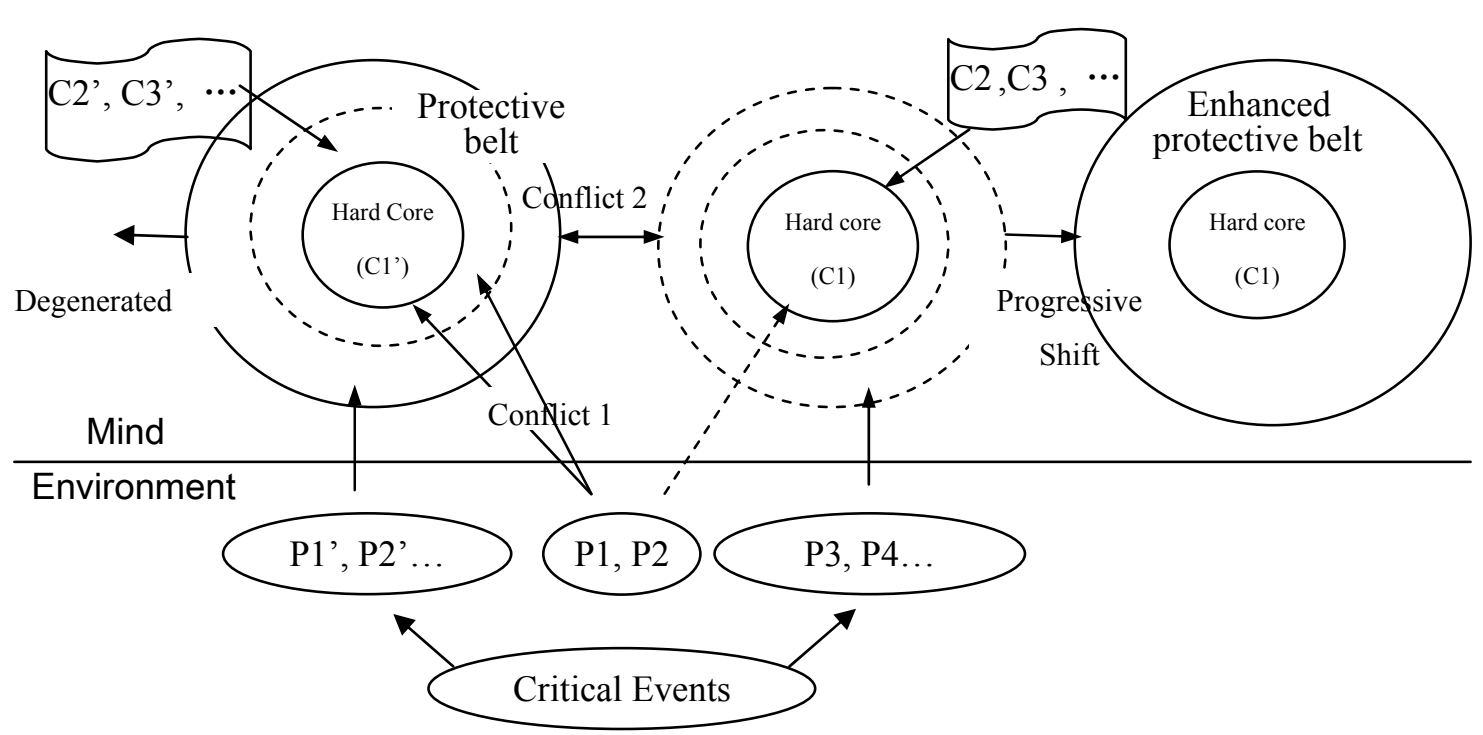

Note: $\mathrm{P} 1$ ', $\mathrm{P} 2$ '... : perceptions protecting existing conception

P1, P2 : perceptions involving a discrepant event

P3, P4 , ... : perceptions supporting Naïve scientific concept

C1..... : the Hard Core of Students' Existing Conception

C1'....: the Hard core of Naïve Scientific Concept

C2', C3' ... : related scientific concepts supporting existing conception $\mathrm{C} 2, \mathrm{C} 3, \ldots$ :

Figure 2. A typical Lakatosian Conflict Map (Modified by Oh, 2011)

Figure 2 in naïve scientific concept tells that in one research program, the core are resistant in change; instead, auxiliary hypotheses verified by experiments are continuously added. The structure of the Lakatosian conflict map: C1 and C2 are rival hard cores, but C2 and C3 are the same hard cores. Hashweh (1986) suggested two types of cognitive conflicts: the conflict between students' preconceptions and the present situation, and the conflict between preconceptions and scientific concepts. The structure of students' existing conceptions by suggested discrepant events must be examined, and students should at least understand about the core theories of the scientific concepts that will be studied to resolve discrepant events.

The teaching process must use a critical events to address conflict 2 . Then, other related scientific concepts will enhance the initial suggested scientific concept, and perceptual supports, examples or phenomena derived from relevant concepts will refine the introduced scientific concepts.

\section{Conclusions and Suggestions}

Generally, dissatisfaction with existing concepts occurs when the existing concepts are not plausible and fruitful. If dissatisfaction arises from an existing concept and detracts from its plausibility, the concept will lose its status and soon be replaced; this can affect one's initial ideas. In this case, it is necessary to reconstruct a new alternative concept. Introducing discrepant events to cause dissatisfaction and systematic reconstruction requires a certain sequence. Thus, this study used Lakatosian methodologies to develop a new, reinforced cognitive teaching model with teaching sequences and strategies.

Michal Matthews(1993, p. 363 refers to the influence of constructivism 'as if a period of Kuhunian normal science has descended upon the science and mathematics education communities'). Kuhn's model of science has been widely influential, but in this research it is argued but it is more appropriate and useful, to consider constructivist research within Science Education as a Lakstosian Methodology. Thargard (1992, p. 257), the one professional philosopher of science who has examined this issue also concluded that children's nave theories have the essential characteristics of scientific theories (Brewer, 2008, p. 178). According to Taber (2009), it can 
certainly be argued that research into topics such as conceptual change can be considered to be science, at least following a Lakatosian model, because Lakatos (1970) would acknowledge that competing research programs can co-exist within a field over extended periods without a dominant paradigm developing to exclude its competitors.

The philosophy of science was adopted. When students realize that their alternative conceptions are partially similar to the ideas of great scientists from the past, they think of themselves as more intelligent. In other words, students are encouraged to think positively about learning new things and changing their existing concepts.

New concepts are learned only when there is relevant background knowledge. Therefore, new concepts must be followed by related knowledge and anticipated phenomena.

A series of discrepant events as well as critical events must be introduced. Students do not respond to a single discrepant event and cannot resolve a conflict between their alternative conceptions and the target scientific concept.

Concepts do not exist separately but form a chain of knowledge.

Therefore, even if one understands a concept accurately, this understanding would be diminished if he also has conflicting concepts or beliefs.

The Lakatosian conflict map includes some important features for promoting conceptual change shown by previous research, such as competing research programs(Lakatos, 1971, p. 103), Conceptual change through revision rather than revolution (Vosniadou, 1994), Evaluating competing research program(Losee, 2001, p. 204). Status (There is the status of students' conceptions. The Lakatosian conflict map provided a useful Instructional framework, not only including a series of discrepant and critical events, perceptions, and concepts, but also investigating the structure of initial conceptions based on Lakatosian methodology by a series of discrepant events, for students to reconstruct from alternative conceptions to target scientific concepts. Thus, they could construct better representations for the target scientific concepts, and resolves a new conflicts between existing alternative conception and new scientific concepts

\section{References}

Barker, P., \& Gholson, B. (1984). In H. W. Reese (Ed.), The history of psychology of learning as a rational process: Lakatos versus Kuhn. Advances in child development and behavior (Vol. 18, pp. 227-244). New York: Academic Press.

Brewer, W. F. (2008). In S. Vosniadou (Ed.), International handbook of research on conceptual change (pp. 155-204). Naïve Theories of Observational Astronomy: Review, Analysis, and Theoretical Implications. New York: Routledge.

Chalmers, A.F. (1999). What is this thing called science? (3rd ed.). Cambridge: Hackett publishing Inc.

Duit, R. (2009). Bibliography-students' and teachers' conceptions and science education. Kiel. Retrieved from http://www.ipn.uni-kiel.de/aktuell/stcse/stcse.html

Duschl, R. A., \& Gitomer, D. H. (1991). Epistemological Perspectives on Conceptual Change: Implications for Educational Practice. Journal of Research in Science Teaching, 28, 839-858. http://dx.doi.org/10.1002/tea.3660280909

Haines-Young, R. H., \& Petch, J. R. (1986). Physical Geography: Its Nature and Methods. London: Harper \& Row Publishers. http://dx.doi.org/10.1080/0140528860080301

Hashweh, M. Z. (1986). Toward an explanation of conceptual change. European Journal of Science Education, $8(3), 229-249$.

Kitchener, R. F. (1987). Genetic Epistemology, Equilibration and the Rationality of scientific Change. Studies in History and Philosophy of Science, 18, 339-366. http://dx.doi.org/10.1016/0039-3681(87)90024-0

Kitchener, R. F. (1999). The Conduct of Inquiry: An Introduction to Logic and scientific Method. Lanham: University Press of America.

Kuhn, T. S. (1970). The structure of scientific revolutions. Chicago: University of Chicago Press.

Lakatos, I. (1970). Criticism and the Growth of Knowledge. In I. Lakatos, \& A. Musgrave (Eds.), Falsification and the Methodology of Scientific Research Programmes. Cambridge: Cambridge University Press.

Lakatos, I. (1971). In R. C. Buck, \& R. S. Cohen (Eds.), History of Science and its Rational Reconstructions (pp. 91-136). Boston Studies in the Philosophy of Science, Vol. VIII, D. Reidel, Dordrecht, The Netherlands. 
Losee, J. (2001). A historical Introduction to the Philosophy of Science (4th ed.). New York: Oxford University Press Inc.

Matthews, M. R. (1993). Constructivism and science education: Some epistemological problems. Journal of Science Education and Technology, 2(1), 359-370. http://dx.doi.org/10.1007/BF00694598

Niaz, M. (1998). A Lakatosian Conceptual change Teaching Strategy Based on Student Ability to Build Models with Varying Degrees of conceptual Understanding of Chemical Equilibrium. Science \& Education, 7(2), 107-127. http://dx.doi.org/10.1023/A:1008671632536

Oh, J. -Y. (2011). Using an enhanced conflict map in the classroom (photoelectric effect) based on lakatosian heuristic principle strategies. International journal of science and mathematics education, 9(5), 1135-1166. http://dx.doi.org/10.1007/s10763-010-9252-1

Oh, J. -Y. (2014). Suggesting a Lakatosian Conflict Map in a Practical Science Teaching Classroom (Unpublished doctoral dissertation). Dankuk University, Republic of Korea.

Oh, J. -Y., Kim, Y. S., \& Park, J. W. (2009). A suggestion of a Lakatosian heuristic teaching sequence model in science education. Paper presented at the Tenth IHPST International Conference (History, Philosophy, Science Teaching Group Conference).

Posner, G., Strike, K. A., Hewson, P. W., \& Gertzog, W. A. (1982). Accommodation of a scientific conception: Toward a theory of conceptual change. Science Education, 66(2), 211-277. http://dx.doi.org/10.1002/sce. 3730660207

Taber, K. S. (2006). Beyond constructivim: The progressive research programme into learning science. Studies in Science Education, 42, 125-184. http://dx.doi.org/10.1080/03057260608560222

Taber, K. S. (2009). Progressing Science Education, Constructing the Scientific Research programme into Contingent Nature of Leaning Science. Dordrecht: Springer.

Thagard, P. (1992). Conceptual revolutions. Priceton, NJ: Priceton University Press.

Tsai, C. -C. (2000). Enhancing science instruction: The use of 'conflict maps. International journal of science education, 22(3), 285-302. http://dx.doi.org/10.1080/095006900289886

Tsai, C. -C., \& Chang, C. -Y. (2005). Lasting Effects of Instruction Guided by the Conflict Map: Experimental Study of Learning about the Causes of the Seasons. Journal of Research in Science Teaching, 42(10), 1089-1111. http://dx.doi.org/10.1002/tea.20089

Vosniadou, S., \& Brewer, W. F. (1994). Mental models of the day/night cycle. Cognitive Science, 18, 123-183. http://dx.doi.org/10.1207/s15516709 $\operatorname{cog} 1801 \_4$

\section{Copyrights}

Copyright for this article is retained by the author(s), with first publication rights granted to the journal.

This is an open-access article distributed under the terms and conditions of the Creative Commons Attribution license (http://creativecommons.org/licenses/by/3.0/). 